\title{
INDUCTION MOTOR CONTROL DIDACTIC SET-UP USING SENSORLESS AND SLIDING MODE DTC STRATEGY
}

\author{
Marcos Vinicius Lazarini and Ernesto Ruppert Filho \\ Electrical and Computer Engineering School \\ University of Campinas (UNICAMP) - Brazil \\ lazarini@dsce.fee.unicamp.br, ruppert@fee.unicamp.br
}

\begin{abstract}
A three-phase induction motor direct torque control laboratory set-up for simulation and experimental activities is presented in this paper. It includes sliding-mode controllers and uses a sensorless method to estimate rotor speed. The objective of this setup is to present to the students a simulation tool based on Matlab SimPowerSystems toolbox with the possibility to check simulation results against a DSP based experimental system. The set-up provides to the electrical engineering students an excellent learning tool for nonlinear control studies using as example the variable speed three-phase induction motor control. Linear control systems are extensively studied in electrical and computer engineering theoretical and experimental sessions while non-linear control systems aren't.
\end{abstract}

Keywords - induction motor, sensorless, sliding mode, torque control, simulation and experimental system

\section{INTRODUCTION}

Among many control methods of induction machines, one of the most important today is the Direct Torque Control (DTC) method introduced by [1] and [2]. It provides a very fast, accurate, reliable flux control and torque responses. It is today one of the most used in the industry.

Sliding Mode Control is presented today as a practical alternative to implement a discontinuous control and has some interesting advantages over the traditional control theory. As a discontinuous control, it has key advantages like the ability to be a very robust control, in many cases invariant to uncertainties and disturbances [3]; it has also properties of order reduction, decoupling design procedure and simple implementation in electric drives, since they have a natural "on-off" operating mode [4].

Sensorless drives are becoming important as they can eliminate the speed sensor maintaining accurate response. Monitoring only the stator current and stator voltages, it is possible to estimate the necessary control variables. The observer type used here is a model-reference adaptive system (MRAS) [5] that presented a good performance.

Simulation tools like Matlab/Simulink are becoming more and more important to aid the engineering studies and designs. Complex systems can be easily simulated, but actually they do not provide practical experience and engineering insight to the students. Experimental systems however are still complex, costly and time-consumption being a real challenge to build them. However such activity

Manuscript received on February 17, 2008; revised on March 13, and on October 10, 2008. Recommended by the Editors of the Special Section, W. I. Suemitsu and J. A. Pomilio. is very useful for a student learning environment so that the non-linear control laboratory set-up, which could feel this pedagogical gap in the control system content, is proposed in this article.

The proposed set-up allows simulation activities of the complete system using developed Matlab SimPowerSystems models, where a concept of modular control algorithm permits that a block diagram could be easily replaced by other. Using the simulation block diagram students can program the DSP and use the DSP based experimental set-up to control the actual electrical machine. The DSP software was developed in separated modules providing a rich framework where students can use various implemented modules in experiments, closely related to simulations.

Using this constructed set-up the students can study, for example, the response of the various DTC controllers' schemes and how they behave when the estimator has detuned parameters [12]. The objective of the experimental set-up and the simulations developed is to show to the students many aspects of the non-linear systems using linear and non-linear controllers. This paper is addressed to show the theoretical foundations of the sensorless DTC of threephase induction motor using sliding mode controllers and MRAS estimator.

The mathematical dynamic model of the DTC three-phase induction motor control, presented in this paper, is based on the papers [6] to [10].

This work intend to be a basis for an electrical and computer engineering course and further references should also be used [4], [5], [11] and [13] to provide adequate foundation to the students.

As far as the authors know there are not more recently published papers presenting so advanced methodology using sensorless and sliding mode DTC strategy.

This work intends to be a basis for a three-phase induction motor control course with theoretical and practical sessions (lab sessions) in a total number of 60 hours where a modern three-phase induction motor control method, that is being widely used in industry (sensorless DTC), be presented using different types of controllers and estimators from the very frequently used PI controllers to the sliding mode control and even possibly non-linear controllers in the future.

The theoretical part of the course must be based on the references [1], [2] and [6] to [9] and the lab sessions will be based in a text that are being prepared at this moment as a result of a master degree thesis on this subject. At the start of the offer of this course it will be offered to graduate students on electrical, mechanical and computer engineering students. Figure 1 shows a block diagram of the implemented system. 


\section{INDUCTION MOTOR CONTROL THEORY FUNDAMENTALS}

Fundamentals of the induction motor control theory applied to the proposed activities are summarized below.

\section{A. Three-phase squirrel-cage induction motor mathematical dynamic model}

Assuming linearity and symmetry of electric and magnetic circuits and also neglecting magnetic core and mechanical losses, the dynamic mathematical model of the three-phase squirrel-cage induction motor referred to a generic $d$ and $q$ perpendicular axis rotating with a generic angular speed $\omega$ can be described with the state variables $\underline{\psi_{s}}, \underline{\psi_{r}}, \underline{i_{s}}$ and $\underline{i_{r}}$, respectively the per-phase stator winding linkage flux space vector, the rotor winding linkage flux space vector, the stator winding current space vector, and the rotor winding current space vector, by the equations (1) to (18) [10]

$$
\begin{gathered}
p \underline{\psi_{s}}=\underline{V_{s}}-r_{s} \underline{i_{s}}-j \omega \underline{\psi_{s}} \\
p \underline{\psi_{r}}=-r_{r} \underline{i_{r}}-j\left(\omega-\omega_{r}\right) \underline{\psi_{r}} \\
\underline{\psi_{s}}=L_{s} \underline{i_{s}}+L_{m} \underline{i_{r}} \\
\underline{\psi_{r}}=L_{r} \underline{i_{r}}+L_{m} \underline{i_{s}} \\
\underline{\psi_{m}}=L_{m}\left(\underline{i_{s}}+\underline{i_{r}}\right)
\end{gathered}
$$

where $V_{s}$ is the motor input voltage space vector, $\omega_{r}$ is the rotor angular speed, $L_{s}$ and $L_{r}$ are the per-phase stator and rotor winding self-inductances, $r_{s}$ and $r_{r}$ are per-phase stator and rotor windings electrical resistances, $L_{m}$ is the per-phase mutual inductance between the stator and the rotor windings and $p$ is the derivative operator $d / d t$. The underline denotes a 2-coordinate vector variable in the dq coordinate system rotating with the angular speed $\omega$. Using (3) and (4) it is possible to write

$$
\begin{gathered}
\underline{\psi_{s}}=\frac{L_{m}}{L_{r}} \underline{\psi_{r}}+\frac{L_{s} L_{r}-L_{m}^{2}}{L_{m}} i_{s} \\
\underline{\psi_{r}}=\frac{L_{m}}{L_{r}} \underline{\psi_{s}}-\frac{L_{s} L_{r}-L_{m}^{2}}{L_{m}} \underline{i_{s}} \\
\underline{i_{s}}=\frac{1}{\sigma L_{s}}\left(\frac{\psi_{s}}{}-\frac{L_{m}}{L_{r}} \underline{\psi_{r}}\right) \\
\underline{i_{r}}=\frac{1}{\sigma L_{s}}\left(-\frac{L_{m}}{L_{r}} \underline{\psi_{s}}+\frac{L_{s}}{L_{r}} \underline{\psi_{r}}\right) \\
\sigma=\frac{\left(L_{s} L_{r}-L_{m}^{2}\right)}{\left(L_{s} L_{r}\right)} .
\end{gathered}
$$

The electromagnetic torque $T_{e m}$ is given by

$$
\underline{T_{e m}}=\frac{3}{2} P\left(\underline{\psi_{s}} \times \underline{i_{s}}\right) .
$$

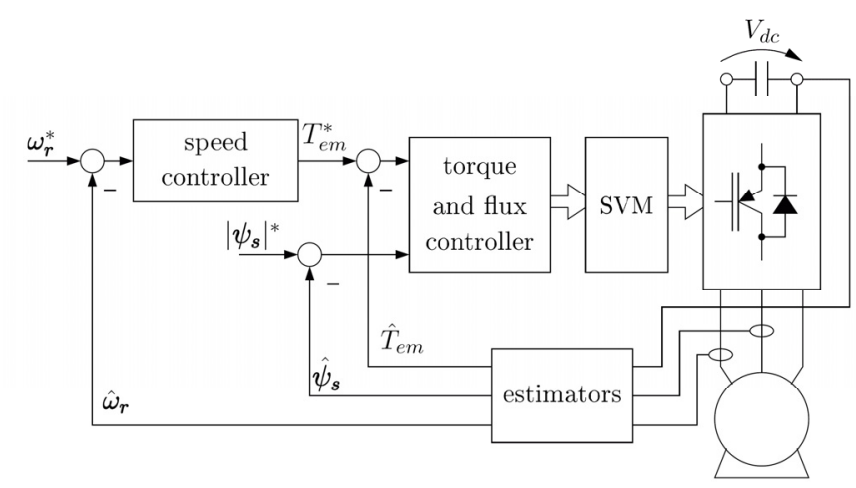

Fig. 1. Overview of the system

Substituting equation (8) in (11) we have

$$
\begin{gathered}
\left|T_{e m}\right|=\frac{3}{2} P \frac{L_{m}}{\sigma L_{s} L_{r}}\left(\underline{\psi_{r}} \times \underline{\psi_{s}}\right) \\
\left|T_{e m}\right|=\frac{3}{2} P \frac{L_{m}}{\sigma L_{s} L_{r}}\left|\psi_{r}\right|\left|\psi_{s}\right| \sin \delta
\end{gathered}
$$

where $P$ is the number of pole pairs and $\delta$ is the angle between space vectors $\psi_{r}$ and $\psi_{s}$. Substituting (8) and (9) in (1) and (2) and fixing the dq reference system in the stator winding $(\omega=0)$ it is possible to write

$$
\begin{gathered}
p \underline{\psi_{s}}=\underline{V_{s}}-\frac{r_{s}}{\sigma L_{s}} \underline{\psi_{s}}+\frac{L_{m} r_{s}}{\sigma L_{s} L_{r}} \underline{\psi_{r}} \\
p \underline{\psi_{r}}=-\frac{r_{r}}{\sigma L_{r}} \underline{\psi_{r}}+\frac{L_{m} r_{r}}{\sigma L_{s} L_{r}} \underline{\psi_{s}}+j \omega_{r} \underline{\psi_{r}} .
\end{gathered}
$$

Remembering the definition of a space vector using the $d$ and q reference system components as presented in equation (15), it is possible to write equations (16) and (17) from (1) with the dq reference system in the stator winding linkage flux as

$$
\begin{gathered}
V_{s}=V_{s d}+j V_{s q} \\
V_{s d}=r_{s} i_{s d}+p \psi_{s d}-\omega_{s} \psi_{s q} \\
V_{s q}=r_{s} i_{s q}+p \psi_{s q}+\omega_{s} \psi_{s d} .
\end{gathered}
$$

Considering that also, $\psi_{s}=\psi_{s d}+j \psi_{s q}$, the electromagnetic torque can also be written from (11) as

$$
T_{e m}=\frac{3}{2} P\left(\underline{\psi_{s}} \times \underline{i_{s}}\right)=\frac{3}{2} P\left(\psi_{s d} i_{s q}-\psi_{s q} i_{s d}\right) .
$$

\section{B. Direct Torque Control}

In the direct torque control method (DTC) of three-phase induction motors supplied by a voltage source inverter, it is 
possible to control directly $\underline{\psi_{s}}$ or $\underline{\psi_{r}}$ or even $\underline{\psi_{m}}$ and $T_{e m}$ by using a selection of adequate inverter switching pattern.

The objective is to maintain the chosen flux and torque errors very small through the adequate choice of the inverter switching pattern so as to get fast torque response, low inverter switching frequency and low harmonic losses. In this work, the stator winding linkage flux space vector $\psi_{s}$ is controlled.

The rotor time constant $\tau_{r}$ of the three-phase squirrel cage induction motor is high when compared to the stator time constant and increases when the size of the machine increases; thus the rotor winding linkage flux changes very slowly compared to the stator winding linkage flux so that it can be assumed to be constant during the discretization period used in the digital control process. If the magnitude of the stator winding linkage flux $\left|\underline{\psi_{S}}\right|$ is maintained constant by the control, $\left|\underline{\psi_{r}}\right|$ is also constant so the electromagnetic torque angle $\delta(12)$ can be changed quickly in the direction determined by the torque command. The angle $\delta$ can be changed by choosing the appropriate stator voltage space vector produced by the inverter. In the case of the filed weakening it is also possible to control both $\left|\underline{\psi_{s}}\right|$ and $\delta$ by switching so that to select the appropriate inverter voltage.

The stator flux linkage space vector depends directly on the stator voltages [12] and can be calculated as the integral of the stator voltage less ohmic losses as

$$
\left.\underline{\psi_{s}}=\int \underline{\left(V_{s}\right.}-r_{s} \underline{i_{s}}\right) d t
$$

In most cases the ohmic voltage drop is small and can be neglected so the flux variations can be approximated considering $r_{s}=0$. Equation (19) shows that the flux variation is then due only to the applied stator voltage. In other words, to control the stator winding linkage flux vector, the inverter generates a stator voltage vector that moves the stator flux to a convenient position; this voltage vector is recalculated at each switching period.

Paper [9], which will be extensively used in the proposed course, presents a very important three-phase squirrel cage induction motor direct torque control review. As reported in [9], there are different schemes to implement DTC for the three-phase induction motor, starting from the first two reported in [1] and [2] to many others based on hysteresis torque and flux control using a switching table (classical method). There are also many others using space vector modulation with controllers like PI, predictive, dead-beat, fuzzy, neuro-fuzzy, sliding mode and also with certain kind of non-linear type controls in a close-loop way.

The disadvantages of the hysteresis-based DTC schemes are: the variable switching frequency, current and torque distortions, problems during starting and low speed operations and the need of high sampling frequency for digital implementation of hysteresis controllers. All these difficulties can be overcame by using voltage PWM modulation instead of a switching table as used in the hysteresis method. This way the sampling frequency will be constant.

One of the objectives of the course proposed here is to show the techniques using hysteresis and voltage PWM modulators, specifically the space vector modulation method to the students using simulation and experimental results.

In the case of the space vector modulation method, there are at least six main methods to be used as mentioned in the literature shown in [9]. In this paper we focused just the one named DTC-SVM scheme with closed-loop torque and flux control operating in cartesian coordinates and stator flux oriented based using a proposal presented in [11]. However in the proposed course, all the six methods will be studied.

In the DTC-SVM scheme shown in Figure 2 a different way to use the idea of the equation (19) is to orient the stator winding flux with the d-axis of the coordinate system (rotating in the synchronous speed) to transform the system of equations (16) and (17) in to the system of equations (20) and (21). The output of the PI flux and torque controllers are the voltages $V_{d s}$ and $V_{q s}$ in the stator flux oriented coordinates. The stator voltages can be expressed in stator flux oriented coordinates as

$$
\begin{gathered}
V_{s d}=r_{s} i_{s d}+p \psi_{s} \approx p \psi_{s}^{*} \\
V_{s q}=r_{s} i_{s q}+\omega_{s} \psi_{s}=K_{s} T_{e m}+\omega_{s} \psi_{s}^{*} .
\end{gathered}
$$

The equations (20) and (21) are obtained by making $\psi_{s d}=\psi_{s}$ and $\psi_{s q}=0$ in (16) and (17). In these equations $\omega_{\mathrm{s}}$ is the synchronous angular speed and

$$
K_{s}=R_{s} / \psi_{s}^{*}
$$

In Figure 3 the output of the PI flux and torque controllers are the voltages $V_{d s}$ and $V_{q s}$ in the stator flux oriented coordinates. The stator voltages can be expressed in stator flux oriented coordinates as it can be seen in (20) where an approximation was made considering $r_{s} i_{d s}$ negligible. The superscripts * means reference value for the control system. Equations (20) and (21) show that for constant magnitude stator flux space vector the $\mathrm{d}$ component of the stator voltage affects the stator flux and can be used to control its position directly. The q component of the stator voltage affects the torque variable, and if the term $\omega_{s} \Psi_{s} *$ is decoupled, it can be used to control the produced torque.

After this transformation it is necessary to implement a $\alpha \beta$ transformation to get $V_{d s}$ and $V_{q s}$ in the stator coordinate system as can be seen in Figure 2. This figure also illustrates the whole control block diagram of the implemented DTC scheme. Of the two PI controllers shown, although recommended by some authors [7], one controller can be removed without significant penalty to the dynamics of the system. Due to the fact that $V_{d s}$ can be approximated by the variation of the stator flux according to (19), the stator winding linkage flux output error $\left(\left|\psi_{s}\right|^{*}-\left|\hat{\psi}_{s}\right|\right)$ already gives the proper variation and can drive $\mathrm{Vds}$ directly. 


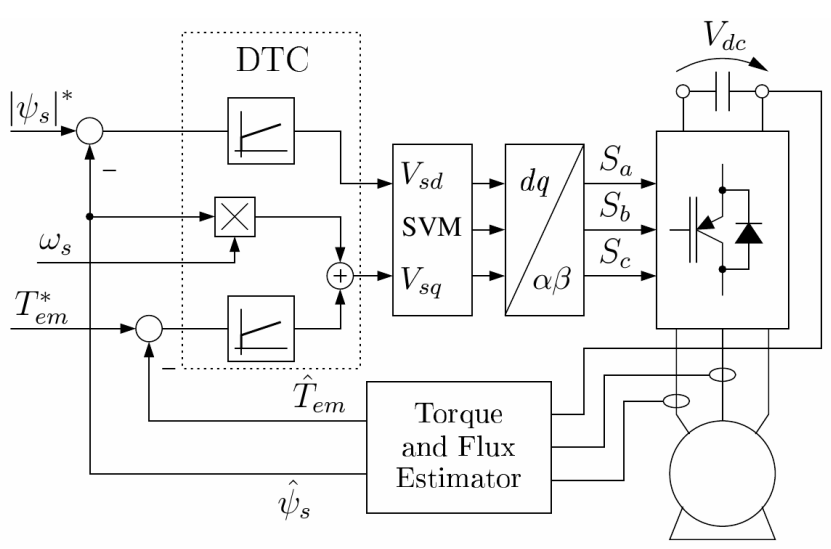

Fig. 2. DTC Block Diagram

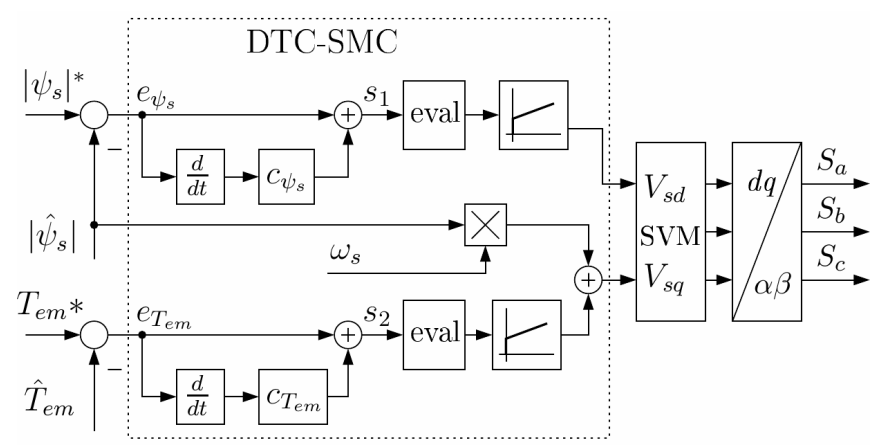

Fig. 3. DTC-Sliding Mode Control Law
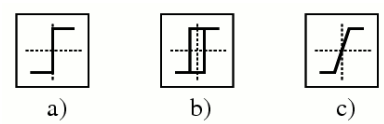

Fig. 4. Typical eval functions: a) sign, b) relay, c) linear with saturation

The control algorithm calculates the magnitude and angle to move the stator flux winding linkage vector to a position producing torque according to (12). Flux vector magnitude is usually hold at rated value to generate the fastest possible response, but it is also possible to work with an underrated flux vector magnitude, in order to have lower acoustic noise and a better energy efficiency machine in specific situations at the cost of a slower response [1].

\section{Sliding Mode Control}

Sliding Mode Control is presented today as a feasible alternative to implement a robust control for the classic DTC scheme taking advantage of the "on-off" inverter switches characteristics and its inherent discontinuous algorithm to control the electrical machine. However the hysteresis control of the classic DTC method causes a major disadvantage that is a variable switching frequency. In order to get a fixed switching frequency operation it is used the space vector modulation strategy that also preserves the good characteristics of the sliding mode control. Implementation in discrete-time digital signal processor also demands changes to avoid unwanted chattering as explained below.

The sliding mode controller was designed to operate over the same variables used in the DTC method. The main goal of this approach is to obtain a sliding mode controller with all the qualities of DTC, which calculates the optimal stator voltage vector to maintain the stator winding linkage flux magnitude and angle within the desired ranges, and outputs this reference to the SVM inverter. The implemented block diagram is shown in Figure 3.

In this figure, the eval block usually is any function of the following family: sign, relay or linear with saturation as shown in Figure 4. Both the sign and the relay functions do not perform accurately in a discrete-time system, resulting in oscillations and undesired chattering. A linear function with a proper gain provides much better results in reducing oscillations while still maintaining the properties of sliding mode [4].

The individual sliding surfaces are designed to behave in a similar way to the DTC control. Firstly are defined the error functions

$$
\begin{gathered}
e_{\psi s}=\left|\psi_{s}\right|^{*}-\left|\hat{\psi}_{s}\right| \\
e_{T e m}=T_{e m}^{*}-\hat{T}_{e m}
\end{gathered}
$$

where the hat symbol means estimated quantity and $e$ is an error value to be minimized.

The sliding surface set $\mathrm{S}$ is defined in (24)

$$
S=\left[\begin{array}{c}
s_{1} \\
s_{2}
\end{array}\right]=\left[\begin{array}{c}
e_{\psi s}+c_{\psi s} \frac{d}{d t}\left(e_{\psi s}\right) \\
e_{T e m}+c_{T e m} \frac{d}{d t}\left(e_{T e m}\right)
\end{array}\right]
$$

where $c_{\psi s}$ e $c_{T e m}$ are constants to be defined according to the desired dynamic response.

The surfaces $s_{1}$ and $s_{2}$ were defined according to (20) and (21), using the same idea that the d stator voltage component is related to the stator flux and q stator voltage component is related to the electromagnetic torque.

The system control law is proposed in a similar way

$$
\begin{aligned}
V_{s d} & =\left(k p_{\psi}+k i_{\psi} \frac{1}{s}\right) \cdot \operatorname{eval}\left(s_{1}\right) \\
V_{s q} & =\left(k p_{T}+k i_{T} \frac{1}{s}\right) \cdot \operatorname{eval}\left(s_{2}\right)+\omega_{s} \hat{\psi}_{s}
\end{aligned}
$$

where $\mathrm{kp}_{\Psi}, \mathrm{ki}_{\Psi}, \mathrm{kp}_{\mathrm{T}}$ and $\mathrm{ki}_{\mathrm{T}}$ are PI gains. The eval function is implemented as a linear gain with saturation, like Figure $4 \mathrm{c}$ )

$$
\operatorname{eval}(x)=\left\{\begin{array}{cc}
k_{e v} x & \text { if lower limit }<x<\text { upper limit } \\
\text { upper limit } & \text { if } x>\text { upper limit } \\
\text { lower limit } & \text { if } x<\text { lower limit }
\end{array}\right.
$$

where $\mathrm{k}_{\mathrm{ev}}$ is a constant related to the system dynamics.

The system's state can start outside the sliding surface but it will be driven in the direction of the sliding surface as control effort will be produced according to (26) to reduce the errors (24) and to reach $S=0$. This phase of the process is named the reaching phase.

When the system state reaches the $\mathrm{S}=0$ surface and enters in the sliding phase or sliding mode, the control law (25) 
restricts the state to the slide surface $\mathrm{S}$ and the system actions is governed by the dynamics imposed by $\mathrm{S}=0$ only. The system state is not allowed to leave the surface, generating a quick and large control effort to keep the system state very close to the sliding surface. This intense reaction, besides producing a very fast response, can also generate undesired ripple as a side-effect of limit cycle in the state space plane. Using the linear function from Figure 4 and with proper gains, the system response could be fast and stable.

The equivalent control is a fundamental theory in variable structure systems that simplify the discontinuous system analysis, replacing discontinuous equations by continuous equivalents, where its trajectory is the sliding surface itself. Therefore it is possible to calculate traditional coefficients, like damping factor and natural frequency for a step response for example. A more detailed view of the background theory and sliding surface design is shown in [4].

\section{Estimator Subsystem}

The adopted estimation structure is a model-reference adaptive system MRAS [5], and it consists of three stage system: two independent estimators and an adaptive mechanism to correct the estimations, producing the final result. An improved model, discussed in [13], was the basic scheme. The adopted structure is presented in Figure 5.

\section{1) Reference Model}

The reference model discussed here is adaptive itself. The stator winding linkage flux is calculated from the stator current and from the rotor winding linkage flux, which gave better results [13]. The rotor winding linkage flux is calculated from a closed loop system. This method, analyzed in details in [13], uses two distinct reference frames to get an improved estimation. The stationary and rotor flux reference frames were used.

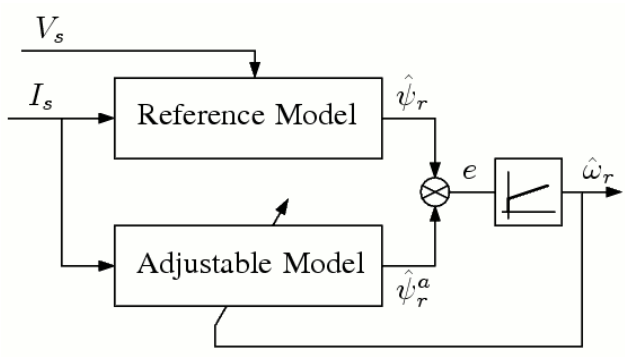

Fig. 5. MRAS Block Diagram

Equation (2) can be also written as (27) and (28). Considering that the rotor winding is short-circuited it has:

$$
\begin{aligned}
& 0=r_{r} i_{r d}+p \psi_{r d}-\left(\omega-\omega_{r}\right) \psi_{r q} \\
& 0=r_{r} i_{r q}+p \psi_{r q}+\left(\omega-\omega_{r}\right) \psi_{r d} .
\end{aligned}
$$

If the rotor flux is aligned with the d-axis of the rotor flux reference coordinate system (see superscript r) it can be written as

$$
\begin{gathered}
p \psi_{r d}^{r}+r_{r} i_{r d}^{r}=0 \\
\psi_{r q}=0 .
\end{gathered}
$$

Using equations (3) and (4) it is possible to show

$$
\begin{gathered}
\underline{i_{r}^{r}}=\frac{\psi_{r}^{r}}{L_{r}}-\frac{L_{m}}{L_{r}} i_{s}^{r} \\
i_{r d}^{r}=\frac{\psi_{r d}^{r}}{L_{r}}-\frac{L_{m}}{L_{r}} i_{s d}^{r} .
\end{gathered}
$$

Substituting (32) in (29)

$$
p \psi_{r d}^{r}+\frac{r_{r}}{L_{r}} \psi_{r d}^{r}-r_{r} \frac{L_{m}}{L_{r}} i_{s d}^{r}=0
$$

Finally it can be written in the form

$$
\underline{\psi_{r}^{r}}=\left[\begin{array}{l}
\psi_{r d}^{r} \\
\psi_{r q}^{r}
\end{array}\right]=\left[\begin{array}{c}
L_{m} /\left(1+s \tau_{r}\right) \cdot i_{s d}^{r} \\
0
\end{array}\right] .
$$

In (34) $\tau_{r}=L_{r} / r_{r}$ is the machine rotor time constant and $L_{m}$ is the machine magnetizing self-inductance, $T_{r}$ is the rotor time-constant and superscript $r$ represents variables referred to the rotor flux reference frame. It is interesting to note that this model uses only stator currents and some machine parameters.

Performing a coordinate system conversion of (34) to the stationary reference frame, the stator flux can be calculated from the rotor flux and stator current as shown in (6) and repeated in (35)

$$
\underline{\hat{\psi}_{s}^{i}}=\frac{L_{m}}{L_{r}} \underline{\psi_{r}}+\frac{L_{s} L_{r}-L_{m}^{2}}{L_{r}} \underline{i_{s}} .
$$

The superscript i denotates the stator flux calculated from the stator currents.

The reference model also calculates the stator flux with another method, through a feedback system where the stator flux estimation $\psi_{s}$ is the feedback variable. A PI represented by $\left(k p_{e}+k i_{e} / s\right)$ - dictates the error contribution between the two flux estimations (35) and (36)

$$
\left.\underline{\dot{\hat{\psi}}_{s}}=\left(\underline{V_{s}}-r_{s} \underline{i}_{s}-\left[\left(k p_{e}+\frac{k i_{e}}{s}\right) \underline{\left(\hat{\psi}_{s}\right.}-\underline{\hat{\psi}_{s}^{i}}\right)\right]\right) .
$$

The index e represents the estimator PI compensators gains. See Figure 6 for a graphical representation of these equations. This model uses now stator currents and voltages. This PI compensator is used to correct pure integrator errors and small stator resistance variation through the voltage model estimation.

The reference model final rotor flux estimation value $\psi_{r}$ is calculated from stator voltages and currents by

$$
\underline{\hat{\psi}_{r}}=\frac{L_{r}}{L_{m}} \underline{\hat{\psi}_{s}}-\frac{L_{s} L_{r}-L_{m}^{2}}{L_{m}} \underline{i_{s}} .
$$




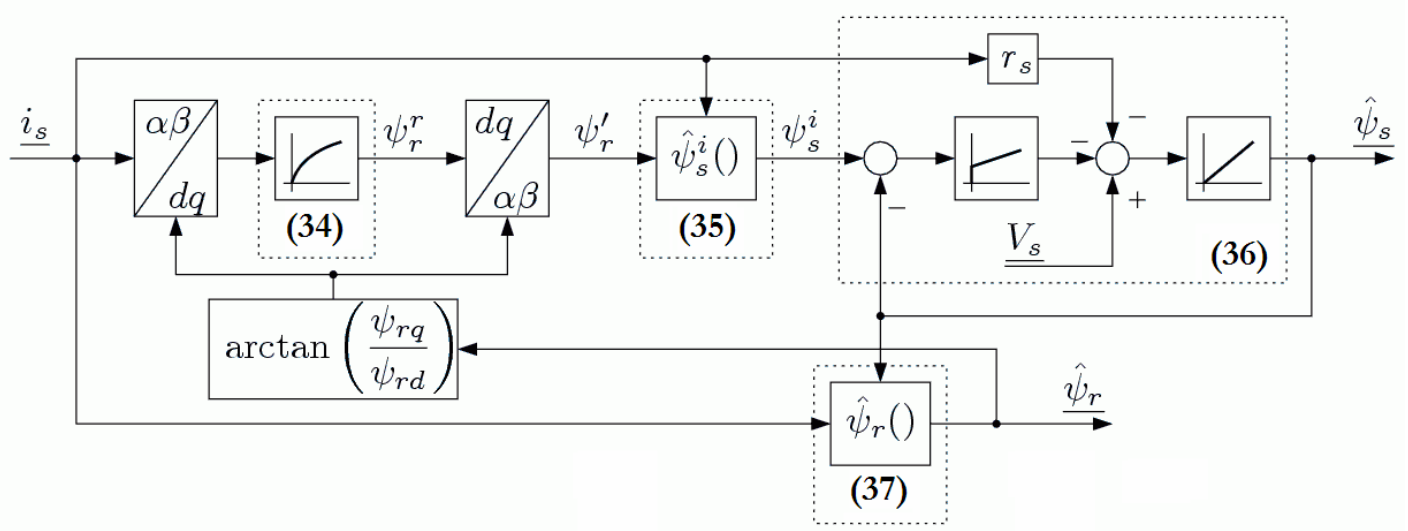

Fig. 6. MRAS reference model

\section{2) Adjustable Model}

The adjustable or adaptive model equation is simpler and is obtained from the current model of the machine equations in stationary reference frame [5] using stator currents and rotor angular velocity

$$
\underline{\hat{\psi}_{r}^{a}}=\left[\begin{array}{cc}
\left(-1 / T_{r}\right) & -\hat{\omega}_{r} \\
\hat{\omega}_{r} & \left(-1 / T_{r}\right)
\end{array}\right] \underline{\hat{\psi}_{r}^{a}}+\frac{L_{m}}{T_{r}} \underline{i}_{s} .
$$

The superscript a denotates the stator flux calculated from the adaptive model.

\section{3) Rotor speed estimation}

With the rotor flux estimation from two methods - the voltage model $\Psi_{\mathrm{r}}$ (reference model) and the current model $\Psi_{\text {ra }}$ (adjustable model) - the rotor speed estimation $\omega_{\mathrm{r}}$ can be calculated with a PI adaptation mechanism by

$$
\hat{\omega}_{r}=\left(k p_{\omega}+\frac{k i_{\omega}}{s}\right) \cdot e
$$

where

$$
e=\hat{\psi}_{r d}^{a} \hat{\psi}_{r q}-\hat{\psi}_{r q}^{a} \hat{\psi}_{r d}
$$

is the cross-error between the adjustable and reference models.

\section{SIMULATION ACTIVITIES}

Simulation tools play a fundamental role in today's engineering educational projects. Using a mathematical model of a given plant, the simulation provides valuable information about the dynamic behavior of the plant, avoiding the high costs of equipment and risk of accidents. Thus, after gaining some experience with the simulation, the students should have an experience with the real system, to test the controllers they have designed and simulated, during the experimental activities using the proposed set-up.

The machine parameters used in the simulation are the same got from the real machine and the system operates in closed-loop with speed feedback from tacogenerator and from the MRAS estimator.
Typical tests situations of a sensorless induction motor control include the load torque step change, reference speed step reversal, reference speed ramp reversal and low speed operation tests.

The proposed simulated scenarios shown in this paper covers the following situations: a step change in the speed reference (from $0.5 \mathrm{pu}$ to $-0.5 \mathrm{pu}$ ) and a step change in torque (from 0 to $0.5 \mathrm{pu}$ ).

The results of step change in the speed reference are presented in Figure 7, where the real speed and estimated speed are shown. Although with small differences, the estimation tracked the real speed very close and it was able to follow the rotor speed within $5 \%$ accuracy most of the time.

The stator flux is also estimated and it is shown in Figure 8. During the start up phase, the stator flux grows from zero to the rated value. The flux magnitude is held constant from this moment on, and this can be verified that the stator flux locus in a xy plane is a circle.

The step change in the torque, from 0 to $0.5 \mathrm{pu}$ at $50 \%$ rated speed is shown in Figure 9. Operating at no load, the speed estimation almost matches the real speed; with $0.5 \mathrm{pu}$ load, the system settle to a new steady state, where the difference between the real and the estimated speed is less than $2 \%$.

The learning activities can also include changes in the controllers' parameters, detuned estimator gains, changes in the motor parameters, autoclosing and changes in the controller types to see their effects on the system response.

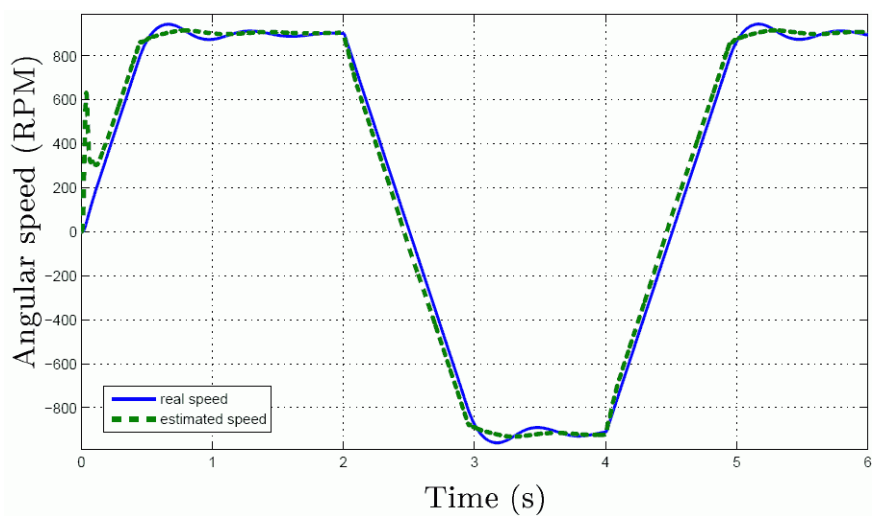

Fig. 7. System response to the reference speed step change $\pm 0.5 \mathrm{pu}$ 


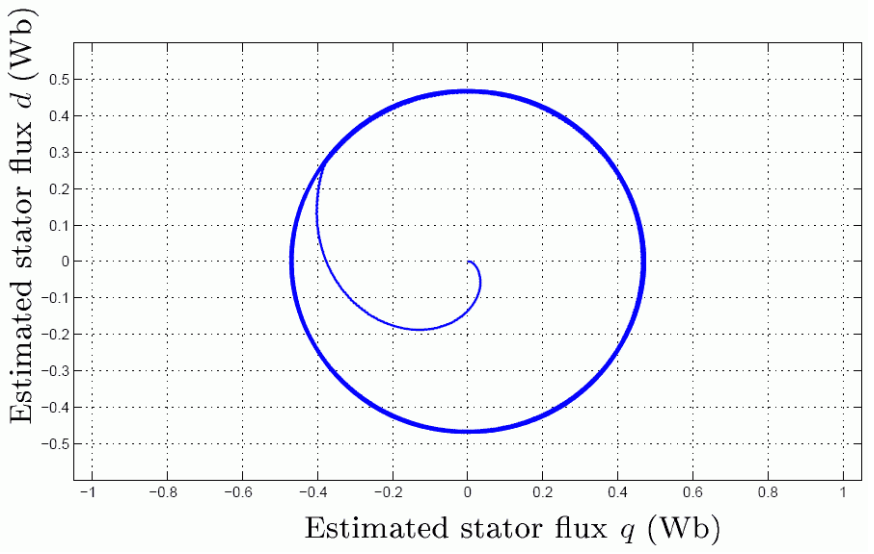

Fig. 8. Stator flux during the speed step change test

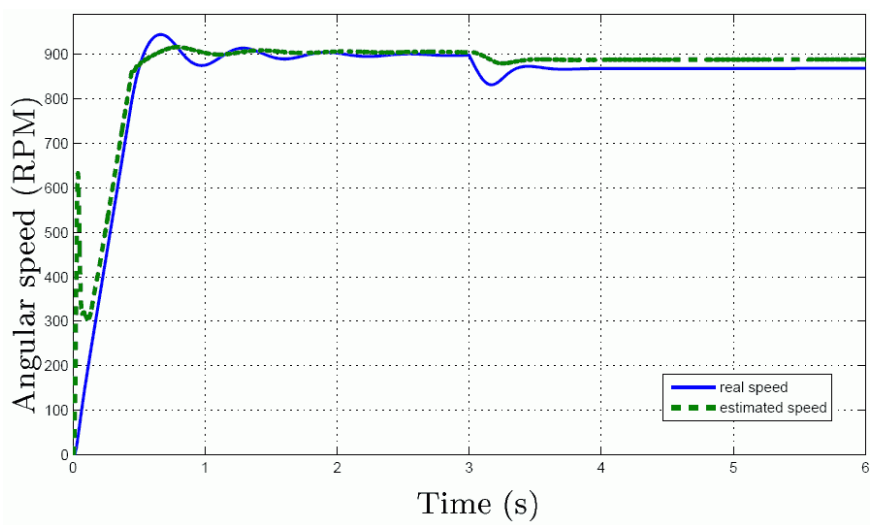

Fig. 9. System response to the load torque step change $0.5 \mathrm{pu}$

\section{EXPERIMENTAL ACTIVITIES}

The experimental activities were realized using the set-up proposed in this article. It includes electronic circuits and electromechanical devices. Figure 10 and 11 display the built experimental setup during the development phase.

The experimental set-up consists of a DSP (Texas Instruments TMS320F2812) connected to an induction motor, driven by a $6 \mathrm{~kW}$ Semikron three-phase inverter (SKS 27F B6U + B6CI 10V06).

The induction motor has a moving frame proper for the electromagnetic torque measurement by a load cell. Load torque can be measured directly in the shaft using another load cell. The load torque that is the torque available at the shaft can also be calculated as the electromagnetic torque minus the losses caused by ventilation and friction. The load is a $\mathrm{CC}$ machine operating as a $\mathrm{CC}$ generator, delivering the produced power to a load resistor. This configuration allows the calculation of the load torque using the voltages and currents produced by the $\mathrm{CC}$ generator.

The used DSP is a high-performance 32 bits RISC Texas Instruments, model TMS320F2812, which runs at $150 \mathrm{MHz}$. It is able to perform complex calculations in real-time, like sophisticated speed estimation methods and digital motor control, and operates at a switching frequency of $10 \mathrm{kHz}$. The DSP has many built-in peripherals, as a 16 channel AD converter and 2 independent PWM modules, providing a lot of resources to implement digital motor control without many external devices.

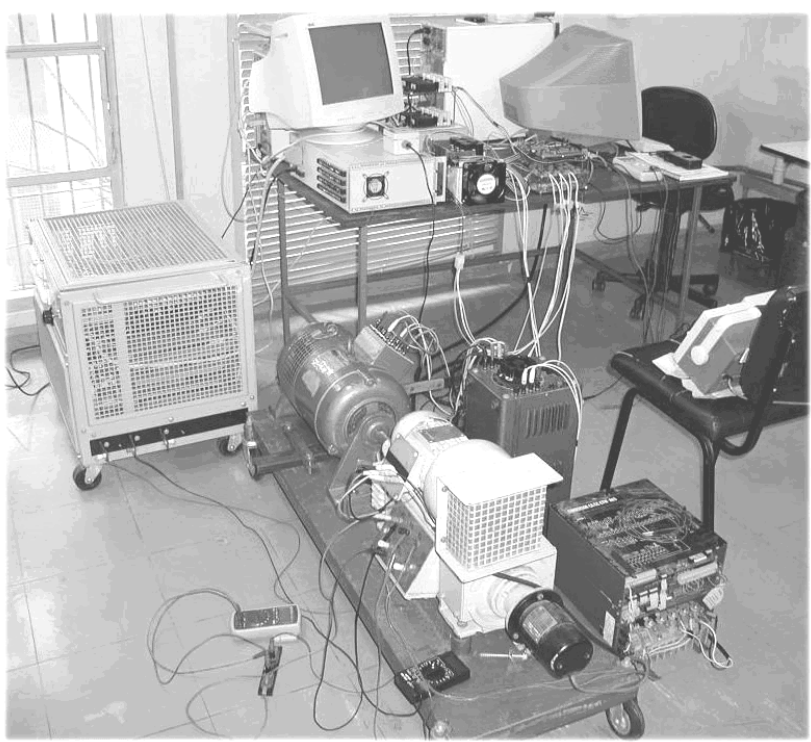

Fig. 10. Experimental set-up showing the electromechanical set (induction motor and its load) and the driving set

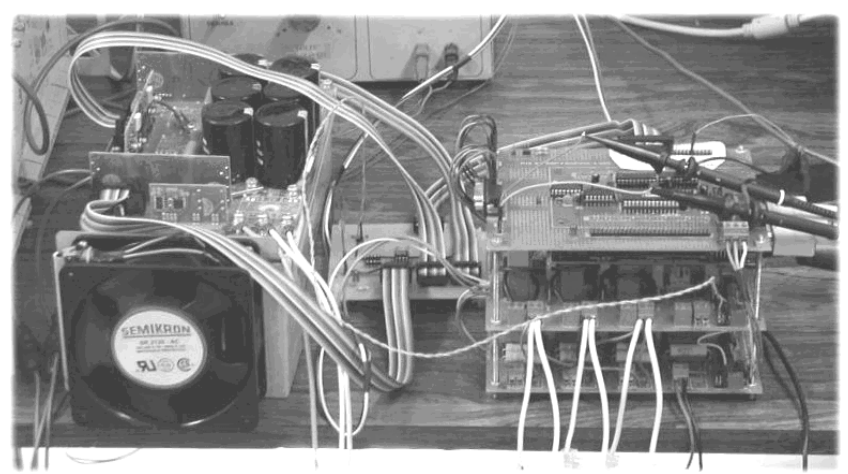

Fig. 11. Inverter (left) and the control circuits tower (DSP and conditioning circuits)

Texas Instruments provides a very complete set of digital motor control foundation libraries, supporting an easy and stable environment for the implementation of the algorithms in a fast pace, an appropriate condition to an educational experiment. Additional routines to control specific subsystems as, e.g., the conditioning signals circuits, the $\mathrm{AD}$ converter and the inverter, were developed and are provided. This way the student can focus on the control algorithm.

A three-phase inverter produced by Semikron is driven by the DSP. It is a $6 \mathrm{~kW}$ inverter, using modules SKS 27F B6U and B6CI 10V06. The DSP has complete access to the inverters IGBTs, allowing the engineer to choose between pre-defined hardware imposed or DSP software controlled dead-time. This permits fine control over the quality of the generate PWM signals, supporting future studies related to unwanted harmonics and EMI effects.

Conditioning signal boards are necessary to acquire the motor state variables from a high level of voltage and current to an appropriate voltage level to be sampled and converted 
by the internal $\mathrm{AD}$ converter. Software routines are provided to remove the residual mean value of AC signals.

Thanks to the powerful DSP, an oversampling technique can be used to sample the voltages and currents, providing better average values of the sampled signals during each switching period of $100 \mu$ s. The sampling frequency can be defined as eight times the switching frequency (i.e. $80 \mathrm{kHz}$ ) using a moving average filter with a uniform weight of $1 / 8$ to smooth each sampled signal. This method has many advantages over traditional sampling and it is also available to the students.

Figure 12 shows the speed reversal test, varying between $+30 \mathrm{~Hz}$ and $-30 \mathrm{~Hz}$ each $2 \mathrm{~s}$. In this test, the estimator gave good results, as both signals were almost superimposed; the steady state error is below $2 \%$. Figure 12 also shows that the breaking is faster than the acceleration, because the friction force wasn't considered in the equations of the motor dynamic mathematical model, but it wasn't negligible in this machine. As a future study is the inclusion of the friction force in the model; however to do so it is necessary to run some experiments to measure the no load mechanical losses.

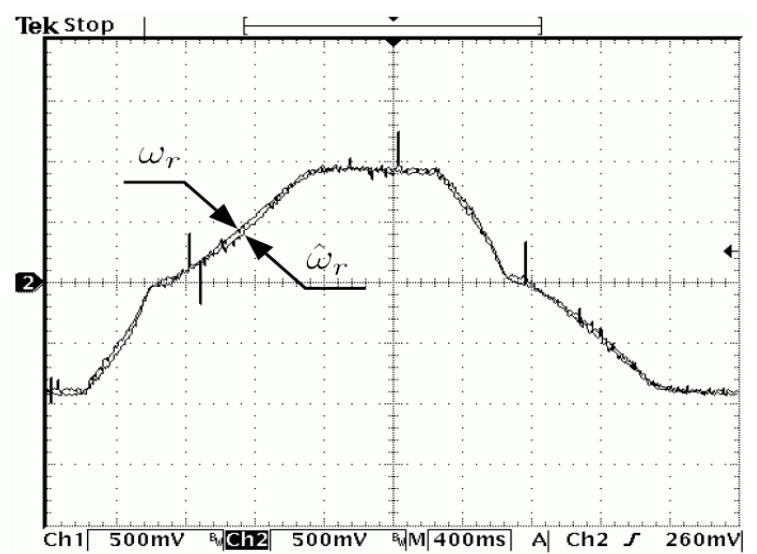

Fig. 12. Real and estimated rotor speed in step change, $\pm 30 \mathrm{~Hz}$ (16 $\mathrm{Hz} /$ div)

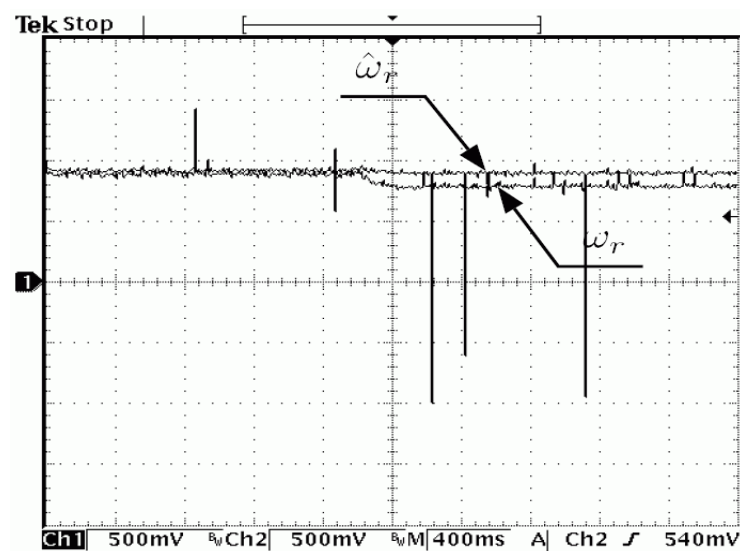

Fig. 13. Speed response to a 0.5 pu torque step change at $30 \mathrm{~Hz}$

In many similar situations to the presented in Figure 9, the experimental set-up has produced the output shown in Figure 13. Although the estimator was not able to track the real speed closely, the oscillations were minimal. The speed error in steady state condition is explained by the fact that the induction motor used in the experiment has wound-rotor and has a rated slip of about $10 \%$. A compensation of this speed error will be made in the future with all the new implementation that will be done.

\section{CONCLUSION}

The main goal of this paper is to propose a laboratory setup for simulation and experimental activities on three-phase induction motor direct torque control experiment, offering learning experience about non-linear control to the students. Different types of controllers (PI and sliding-mode controllers) and a sensorless method to estimate rotor speed can also be used and their responses can be analyzed though only sliding mode controller and MRAS estimator were presented now. Results are very clear, illustrative and proper encourage to prepare several types of learning activities according to the instructor imagination.

The proposed set-up and activities allow electrical engineering students (undergraduate and graduate) to experience the difficulties and particularities of non-linear systems and non-linear controllers. Using as example the variable speed three-phase induction motor control, there are plenty of good situations to be exploited by the faculties and the assistant teachers involved with the teaching of control and electrical machines.

\section{ACKNOWLEDGMENT}

The authors are grateful to FAPESP - the State of São Paulo Research Foundation - and to $\mathrm{CNPq}$ - Brazilian National Research Council - for the financial support and to Texas Instruments for the DSP donation.

\section{REFERENCES}

[1] I. Takahashi and T. Noguchi, "A new quick response and high efficiency control strategy of an induction motor", IEEE Transactions on Industry Applications, vol. 22, pp. 820-827, 1986.

[2] M. Depenbrock, "Direct self-control (DSC) of inverterfed induction machine", IEEE Transactions on Power Electronics, vol. 3, no. 4, pp. 420-429, 1988.

[3] J. Hung, W. Gao, and J. Hung, "Variable structure control: a survey", IEEE Transactions on Industrial Electronics, vol. 40, no. 1, pp. 2-22, 1993.

[4] V. Utkin, J. Guldner, and J. Shi, Sliding Mode Control in Electromechanical Systems, CRC Press, 1999, ISBN: 0748401164.

[5] C. Schauder, "Adaptive speed identification for vector control of induction motors without rotational transducers", IEEE Transactions on Industry Applications, vol. 28, no. 5, pp. 1054-1061, 1992.

[6] C. Lascu, I. Boldea, and F. Blaabjerg, "A modified direct torque control for induction motor sensorless", IEEE Transactions on Industry Applications, vol. 36, no. 1, pp. 122-130, 2000. 
[7] C. Lascu, I. Boldea, and F. Blaabjerg, "Direct torque control of sensorless induction motor drives: a slidingmode approach", IEEE Transactions on Industry Applications, vol. 40, no. 2, pp. 582-590, 2004.

[8] P. Vas, Sensorless Vector and Direct Torque Control, Oxford University Press, 1998, ISBN: 0198564651.

[9] G. Buja and M. Kazmierkowski, "Direct torque control of PWM inverter-fed AC motors - a survey", IEEE Transactions on Industrial Electronics, vol. 51, no. 4, pp. 744-757, 2004.

[10]P. K. Kovacs, Transient Phenomena in Electrical Machines, Elsevier, 1984

[11] Y. Xue, X. Xu, T. Habetler, and D. Divan, "A low cost stator flux oriented voltage source variable speed drive", in Conference Record of the 1990 IEEE Industry Applications Society Annual Meeting, vol.1, pp. 410 415, 1990.

[12] M. P. Kazmierkowski, Control in Power Electronics: Selected Problems (Academic Press Series in Engineering). Academic Press, 2002.

[13] P. Jansen, R. Lorenz, and D. Novotny, "Observer-based direct field orientation: analysis and comparison of alternative methods", IEEE Transactions on Industry Applications, vol. 30, no. 4, pp. 945-953, 1994.

\section{BIOGRAPHIES}

Marcos Vinicius Lazarini was born in São José dos Campos, Brazil on May 29, 1978. He received his Bsc degree in Computer Engineering with emphasis in hardware development from University of Campinas, Brazil, in 2004 and now is pursuing his $\mathrm{M}$. Sc degree in Electrical Engineering from Unicamp.

His research interests are in programming for embedded devices in general, digital signal processing theory and control theory applied to motor drives.

Ernesto Ruppert Filho was born in Jundiaí, Brazil in 1948. He received his $\mathrm{Ph}$. D degree on Electrical Engineering in 1983 from University of Campinas (UNICAMP), Brazil and also his M. Sc Degree in 1974 and his B. Sc in 1971 in Electrical Engineering from the same University.

He is with UNICAMP as a Faculty since 1972 working in the areas of electrical energy systems, electrical machines and power electronics. He had been working for General Electric and also for Villares Electrical Equipments in Brazil designing motors and generators for about 15 years. His fields of interest now are superconductor current limiters, control of electrical machines and power electronics, areas where he published several papers. 